University of Wollongong

Research Online

Australian Institute for Innovative Materials -

Papers

Australian Institute for Innovative Materials

$1-1-2017$

Same titanium glycolate precursor but different products: Successful synthesis of twinned anatase TiO2 nanocrystals with excellent solar photocatalytic hydrogen evolution capability

\author{
Gang Cheng \\ Wuhan Institute of Technology \\ Yi Wei \\ Wuhan Institute of Technology \\ Jinyan Xiong \\ Wuhan Textile University, University of Wollongong, jx513@uowmail.edu.au \\ Yixin Gan \\ Wuhan Institute of Technology \\ Jiaxin Zhu \\ Wuhan Institute of Technology
}

See next page for additional authors

Follow this and additional works at: https://ro.uow.edu.au/aiimpapers

Part of the Engineering Commons, and the Physical Sciences and Mathematics Commons

Research Online is the open access institutional repository for the University of Wollongong. For further information contact the UOW Library: research-pubs@uow.edu.au 


\title{
Same titanium glycolate precursor but different products: Successful synthesis of twinned anatase TiO2 nanocrystals with excellent solar photocatalytic hydrogen evolution capability
}

\begin{abstract}
Exploiting a synthesis protocol to tailor TiO 2 with a unique morphology and crystal phase has received considerable interest in the energy and environmental fields. We here describe the use of a titanium glycolate precursor in a hydrothermal hydrolysis reaction to engineer TiO 2 nanocrystals with different crystal phases and structures. Anatase TiO 2 nanocrystals with twinned structures were obtained by using a lower amount of $\mathrm{NaOH}$ in the hydrolysis system, while brookite $\mathrm{TiO} 2$ nanocrystals were formed when higher amounts of $\mathrm{NaOH}$ were employed. The as-synthesized different $\mathrm{TiO} 2$ nanocrystals have a suitable bandgap to harvest photons and a more negative bottom level of the conduction band than the redox potential of $\mathrm{H}+/ \mathrm{H} 2$ indicating their potential as hydrogen-evolution semiconductor photocatalysts. However, the TiO 2 nanotwins show promoted charge separation efficiency, and thus result in superior photocatalytic $\mathrm{H} 2$ generation activity compared to the anatase and brookite TiO 2 nanocrystals. Our findings provide an effective and versatile solution for the fabrication of TiO 2 -based nanostructures with different phases and morphologies through chemical conversion of powder precursor nanoparticles, which could pave the way to the design of other functional nano-oxides with unique structures.

\section{Disciplines \\ Engineering | Physical Sciences and Mathematics}

\section{Publication Details}

Cheng, G., Wei, Y., Xiong, J., Gan, Y., Zhu, J. \& Xu, F. (2017). Same titanium glycolate precursor but different products: Successful synthesis of twinned anatase $\mathrm{TiO} 2$ nanocrystals with excellent solar photocatalytic hydrogen evolution capability. Inorganic Chemistry Frontiers, 4 (8), 1319-1329.
\end{abstract}

\section{Authors}

Gang Cheng, Yi Wei, Jinyan Xiong, Yixin Gan, Jiaxin Zhu, and Feifan Xu 


\section{Check for updates}

Cite this: Inorg. Chem. Front., 2017, 4, 1319

Received 21st May 2017

Accepted 19th June 2017

DOI: $10.1039 /$ c7qi00278e

rsc.li/frontiers-inorganic

\section{Same titanium glycolate precursor but different products: successful synthesis of twinned anatase $\mathrm{TiO}_{2}$ nanocrystals with excellent solar photocatalytic hydrogen evolution capability $\dagger$}

\author{
Gang Cheng, (D)*a Yi Wei, ${ }^{a}$ Jinyan Xiong, ${ }^{b, c, d}$ Yixin Gan, ${ }^{a}$ Jiaxin Zhu ${ }^{a}$ and Feifan $X^{a}$
}

Exploiting a synthesis protocol to tailor $\mathrm{TiO}_{2}$ with a unique morphology and crystal phase has received considerable interest in the energy and environmental fields. We here describe the use of a titanium glycolate precursor in a hydrothermal hydrolysis reaction to engineer $\mathrm{TiO}_{2}$ nanocrystals with different crystal phases and structures. Anatase $\mathrm{TiO}_{2}$ nanocrystals with twinned structures were obtained by using a lower amount of $\mathrm{NaOH}$ in the hydrolysis system, while brookite $\mathrm{TiO}_{2}$ nanocrystals were formed when higher amounts of $\mathrm{NaOH}$ were employed. The as-synthesized different $\mathrm{TiO}_{2}$ nanocrystals have a suitable bandgap to harvest photons and a more negative bottom level of the conduction band than the redox potential of $\mathrm{H}^{+} / \mathrm{H}_{2}$ indicating their potential as hydrogen-evolution semiconductor photocatalysts. However, the $\mathrm{TiO}_{2}$ nanotwins show promoted charge separation efficiency, and thus result in superior photocatalytic $\mathrm{H}_{2}$ generation activity compared to the anatase and brookite $\mathrm{TiO}_{2}$ nanocrystals. Our findings provide an effective and versatile solution for the fabrication of $\mathrm{TiO}_{2}$-based nanostructures with different phases and morphologies through chemical conversion of powder precursor nanoparticles, which could pave the way to the design of other functional nano-oxides with unique structures.

\section{Introduction}

Titanium dioxide $\left(\mathrm{TiO}_{2}\right)$ is regarded as one of the most promising semiconducting materials on account of its excellent physicochemical properties and great potential in the energy and environmental fields. Evidence indicates that the performance of $\mathrm{TiO}_{2}$-based materials can be varied by changing not only the crystal phase but also the structure of the $\mathrm{TiO}_{2} \cdot{ }^{1-3}$ Study of the intrinsic relationship between the phase/ morphology and properties of $\mathrm{TiO}_{2}$-based materials has engendered an urgent need for adjustable synthetic strategies, where the crystal phase and particle structure of $\mathrm{TiO}_{2}$ nanomaterials can be precisely controlled with designed functionalities. ${ }^{4-9}$ However, synthetic techniques for preparing such nanostructured materials, especially those achieving simultaneous

\footnotetext{
${ }^{a}$ School of Chemistry and Environmental Engineering, Wuhan Institute of Technology, Xiongchu Avenue, Wuhan, 430073, PR China. E-mail: gchenglab@163.com

${ }^{b}$ College of Chemistry and Chemical Engineering, Wuhan Textile University, Wuhan 430200, PR China

${ }^{c}$ Hubei Key Laboratory of Biomass Fibers and Eco-dyeing \& Finishing, Wuhan Textile University, Wuhan, 430073 Hubei, PR China

${ }^{d}$ Institute for Superconducting and Electronic Materials, University of Wollongong, Innovation Campus, Squires Way, North Wollongong, NSW 2500, Australia

$\dagger$ Both Dr Cheng and Dr Xiong would like to send their congratulations on the occasion of the tenth anniversary of the foundation of Prof. Rong Chen's group.
}

control of both the crystal phase and the morphology, still remain a challenge because of the rapid hydrolysis of titanium alkoxides and titanium tetrachloride, which are widely used as titanium precursors. Therefore, on the one hand, much attention has been paid to the control of hydrolysis using alcohol or chelating agents, such as dihydric alcohol or carboxylic acid, or other additives. ${ }^{10-13}$ On the other hand, substantial efforts have been made toward the development of a new suitable titanium precursor with a proper transformation process to selectively prepare $\mathrm{TiO}_{2}$ with tunable phases and structures, as well as avoiding the involvement of complex experimental processes.

One dimensional titanate nanofibers/nanorods/nanotubes are one of the most widely used precursors to prepare $\mathrm{TiO}_{2}$ nanostructures via thermal dehydration reactions or hydrothermal treatments. ${ }^{14-19}$ However, the use of titanate nanowires derived from the alkali treatment of $\mathrm{TiO}_{2}$ nanoparticles under highly basic conditions requires complex post-processing processes; meanwhile, $\mathrm{TiO}_{2}$ nanocrystals prepared by the hydrothermal transformation of titanate are limited to a single crystal phase of anatase or rutile. Wang et $a .^{20}$ reported a onepot and template-free strategy for synthesizing hollow $\mathrm{TiO}_{2}$ nanostructures using titanocene dichloride $\left(\mathrm{Cp}_{2} \mathrm{TiCl}_{2}\right)$ as the titanium source, but other chemicals (acetone and ammonia) were also involved in the reaction system. Other titanium 
precursors have also been prepared to fabricate $\mathrm{TiO}_{2}$ nanomaterials. For example, $\mathrm{TiO}_{2}$ nanoparticles were prepared with strict control of the size, molecular mass, and mass density by hydrolyzing a precursor, Ti-(acac) $)_{2}$ (biphen), in the presence of a well-defined hollow $\operatorname{Pd}_{12} \mathrm{~L}_{24}$ spherical endotemplate. ${ }^{21}$ Unique spindle-shaped nanoporous anatase $\mathrm{TiO}_{2}$ mesocrystals with a single-crystal-like structure and tunable sizes were also successfully fabricated through calcination treatment of precursors prepared in a tetrabutyl titanate-acetic acid system under solvothermal conditions. ${ }^{22}$ In addition, titanium glycolate precursors prepared from titanium alkoxides and ethylene glycol are considered as a potential precursor for preparing $\mathrm{TiO}_{2}$. Xia's group synthesized $\mathrm{TiO}_{2}$ nanowires and nanospheres via annealing treatment of prepared titanium glycolate precursors, and demonstrated that the titanium glycolate could be transformed into the amorphous phase of $\mathrm{TiO}_{2}$ at $350{ }^{\circ} \mathrm{C}$, the anatase phase at $500{ }^{\circ} \mathrm{C}$, and the rutile phase at $850{ }^{\circ} \mathrm{C} . .^{23,24}$ Zhong et al. synthesized highly nanoporous $\mathrm{TiO}_{2}$ (anatase) spheres via in situ hydrolysis of titanium glycolate precursor spheres. ${ }^{25}$ However, the disadvantage of the above mentioned synthesis strategies is that the synthesized $\mathrm{TiO}_{2}$ shows a similar morphology or size to the precursors, because the precursors act as a hard template in the process of annealing the precursor powders.

In previous work, we successfully synthesized $\mathrm{TiO}_{2} @$ carbon material hybrid nanostructures via a nanoprecursor-involved hydrothermal process, ${ }^{26-28}$ in which the spherical titanium glycolate precursors were hydrolyzed into titanium oxide from a nanoporous to a nanoparticulate structure. This phenomenon inspired us to manipulate the stability and transformation of titanium glycolate precursors by adjusting the experimental conditions involved in the wet-chemical synthesis and to study their effects on the formation and growth of the final $\mathrm{TiO}_{2}$ nanocrystals. Herein, the structure and crystal phase of the $\mathrm{TiO}_{2}$ products were successfully engineered from this titanium glycolate precursor via the use of $\mathrm{NaOH}$, which was confirmed by powder X-ray diffraction and scanning/transmission electron microscopy. To the best of our knowledge, there are few literature reports related to the phase and structure controlled synthesis of $\mathrm{TiO}_{2}$ through a wet-chemical approach using powder precursors. Interestingly, twinned anatase $\mathrm{TiO}_{2}$ nanocrystals were prepared for the first time in the presence of a lower amount of $\mathrm{NaOH}$, and also displayed promoted charge separation efficiency for a superior photocatalytic capability towards hydrogen generation.

\section{Experimental section}

\subsection{Synthesis}

All of the reagents were of analytical grade and were used without further purification. De-ionized water was used in all experiments. The titanium glycolate precursor was synthesized according to our previously reported procedure. ${ }^{26,29,30}$ In a typical synthesis, $2 \mathrm{~mL}$ of tetrabutoxytitanium was added to $50 \mathrm{~mL}$ of ethylene glycol and was magnetically stirred for
2 hours at $60{ }^{\circ} \mathrm{C}$ in a water bath. After cooling down to room temperature, the mixture was poured into a mixed solution of acetone and de-ionized water $(\mathrm{v} / \mathrm{v}=150 \mathrm{~mL} / 30 \mathrm{~mL})$. The precipitate was collected and washed with de-ionized water and ethanol six times by centrifugation, then dried at $60{ }^{\circ} \mathrm{C}$ overnight for further use.

Twinned $\mathrm{TiO}_{2}$ nanocrystals were prepared by a hydrothermal method from the as-synthesized titanium glycolate precursor. In a typical synthesis, $0.1 \mathrm{~g}$ of the as-synthesized titanium glycolate precursor was dispersed in $30 \mathrm{~mL}$ of deionized (DI) water under vigorous sonication. Next, $0.5 \mathrm{mmol}$ $\mathrm{NaOH}$ was added into the above homogeneous solution and then the mixture was transferred into a $50 \mathrm{~mL}$ Teflon-lined autoclave and maintained at a temperature of $180^{\circ} \mathrm{C}$ for $18 \mathrm{~h}$. After cooling down to room temperature, the products were collected and washed with de-ionized water and ethanol several times by centrifugation. The final product was dried for $12 \mathrm{~h}$ at $60^{\circ} \mathrm{C}$. The effect of the amount of $\mathrm{NaOH}$ on the formation and structure of the twinned $\mathrm{TiO}_{2}$ nanocrystals was investigated under the same synthesis conditions, except for the tuning of the $\mathrm{NaOH}$ concentration.

\subsection{Characterization}

The titanium glycolate precursor and $\mathrm{TiO}_{2}$ samples were characterized by powder X-ray diffraction (XRD), scanning electron microscopy (SEM), transmission electron microscopy (TEM), and selected area electron diffraction (SAED). XRD was carried out on a multi-purpose high performance X-ray diffractometer ( $\mathrm{CuK} \alpha$ radiation, $\lambda=1.54 \AA$ ) at a scanning rate of $0.03^{\circ} \mathrm{s}^{-1}$ in the $2 \theta$ range from $10^{\circ}$ to $90^{\circ}$. SEM images were taken on a field-emission electron microscope (ZEISS, SUPRA 40VP) operating at an acceleration voltage of $3 \mathrm{kV}$. TEM images, high resolution TEM images, and SAED patterns were recorded on a JEOL 2010 electron microscope at an accelerating voltage of $200 \mathrm{kV}$. Photoluminescence spectra (PL) were detected with a HITACHI (Japan) F4600 Fluorescence spectrophotometer.

The photocurrent measurements were performed similar to previous reports ${ }^{28}$ and conducted on a CHI 660E electrochemical system (Shanghai, China) using a standard threeelectrode cell with a working electrode, a platinum wire counter electrode, and a saturated calomel electrode (SCE) reference electrode. A solution containing $0.5 \mathrm{M} \mathrm{Na}_{2} \mathrm{SO}_{4}$ was used as the electrolyte. The working electrode was prepared according to the following process: $20 \mathrm{mg}$ of as-prepared sample was mixed with $1 \mathrm{~mL}$ of DMF and $0.01 \mathrm{~mL}$ of Nafion solution (5\%, DuPont) to form a homogeneous ink. Then $0.1 \mathrm{~mL}$ of the photocatalyst ink was dip-coated onto a $10 \mathrm{~mm} \times$ $10 \mathrm{~mm}$ indium-tin oxide (ITO) glass electrode. The estimated loading amount of the sample is $2 \mathrm{mg} \mathrm{cm}{ }^{-2}$. After drying at room temperature, the as-prepared electrode was further annealed at $150{ }^{\circ} \mathrm{C}$ for $4 \mathrm{~h}$ in a vacuum oven to remove the resin. The photocurrent responses of the photocatalyst in the presence and absence of light were measured at open-circuit potential, with simulated light irradiation provided by a $500 \mathrm{~W}$ Xe lamp. Electrochemical impedance spectroscopy (EIS) was 
carried out at open-circuit potential in $0.5 \mathrm{M}$ potassium ferricyanide solution. The samples were dip coated onto a glassy carbon working electrode. A sinusoidal AC perturbation of $5 \mathrm{mV}$ was applied to the electrode over the frequency range of $0.5-10^{5} \mathrm{~Hz}$.

\subsection{Photocatalytic hydrogen generation test}

Photocatalytic hydrogen evolution experiments were conducted under vacuum conditions in a $500 \mathrm{~mL}$ quartz reactor with a top quartz window allowing for light irradiation (CEL-SPH2N, CEAULIGHT Beijing). Actually, the procedure is similar to our previous method. ${ }^{31}$ Typically, $50 \mathrm{mg}$ of photocatalyst was added into methanol solution (vol 20\%), which was used as a sacrificial electron donor, and the mixture was subjected to ultrasonic treatment for $15 \mathrm{~min}$. A $300 \mathrm{~W}$ Xe lamp was used as an artificial sunlight source. Before light irradiation, the quartz reactor was sealed gas-tightly with high vacuum grease and purged by vacuumization to remove the residual air. During the hydrogen generation reaction, the suspension was exposed under simulated solar light irradiation with continuous stirring. The volume of generated hydrogen was analyzed by on-line gas chromatography with a TCD detector at set intervals. All the hydrogen evolution experiments were carried out at room temperature.

\section{Results and discussion}

Fig. 1a shows the XRD pattern of the sample prepared from the titanium glycolate nanoprecursor with the involvement of $0.5 \mathrm{mmol} \mathrm{NaOH}$ in the reaction system. All diffraction peaks can be assigned to the anatase phase (JCPDS no. 71-1167), which confirmed the high purity of the product. The microstructural characteristics of the $\mathrm{TiO}_{2}$ material were also analysed by Raman scattering. As shown in Fig. 1b, the material displays four bands at 152, 400, 516, and $637 \mathrm{~cm}^{-1}$, corresponding to the characteristic Raman modes $\mathrm{E}_{\mathrm{g}}(1), \mathrm{B}_{1 \mathrm{~g}}(1), \mathrm{A}_{1 \mathrm{~g}}+$ $\mathrm{B}_{1 \mathrm{~g}}(2)$, and $\mathrm{E}_{\mathrm{g}}(2)$ of anatase $\mathrm{TiO}_{2}$, respectively. This indicates the presence of the anatase phase in the as-prepared materials, which is in accordance with the XRD results.

The morphology and structure of the as-synthesized $\mathrm{TiO}_{2}$ sample were further characterized using SEM, TEM, and HRTEM images, and SAED patterns. In Fig. 2a, it was observed from the SEM image that large amounts of nanoparticles were obtained. The TEM image shown in Fig. $2 \mathrm{~b}$ reveals that the $\mathrm{TiO}_{2}$ nanoparticles have a diameter of about $50 \mathrm{~nm}$. Furthermore, it could be seen that some nanoparticles have a shared edge like a fastigium. The HRTEM images (Fig. 2d and e) clearly depict that the $\mathrm{TiO}_{2}$ nanoparticles have a twinned structure and two nanocrystals share a back like a fastigium in a Beijing traditional courtyard (Fig. 2c), which might be attributed to the growth occurring along the same zone axis. As shown in Fig. 2d, the distance between the two consecutive planes from the central of such twinned nanocrystals is measured to be $0.35 \mathrm{~nm}$ from the lattice image, which matches the distance between two consecutive (101) planes of
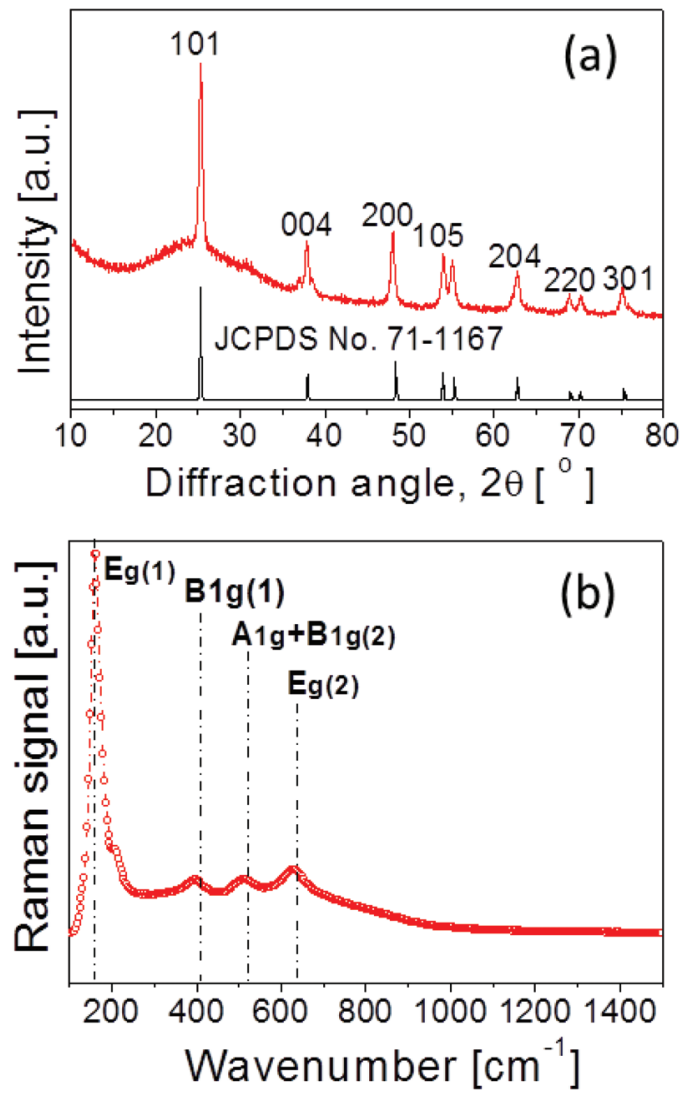

Fig. 1 (a) XRD pattern and (b) Raman spectrum of the as-synthesized twinned $\mathrm{TiO}_{2}$ anatase nanocrystals.

bulk $\mathrm{TiO}_{2}$, indicating that the twinned nanocrystals have the same exposed facets. ${ }^{32}$ The SAED pattern in Fig. $2 \mathrm{f}$ was characteristic of a polycrystalline structure of $\mathrm{TiO}_{2}$, and several diffraction ring patterns corresponding to the (101), (004), (200), and (211) planes are the sum of different single-crystallized $\mathrm{TiO}_{2}$ nanoparticles.

As a matter of fact, it was found that the amount of $\mathrm{NaOH}$ has a significant impact on the structure and crystal phase of the final titanium oxide nanocrystals. Fig. 3 shows the XRD patterns of the as-synthesized products in the presence of different amounts of $\mathrm{NaOH}$. It was found that a low concentration of $\mathrm{NaOH}$ could not tailor the crystal phase, and the final products exhibit the anatase phase when less than $0.5 \mathrm{mmol} \mathrm{NaOH}$ is used. As shown in Fig. $4 \mathrm{a}$ and b, the asprepared titanium glycolate precursor exhibits an amorphous phase and aggregated nanoparticulate morphology. When the precursor powders were hydrothermally treated in water, the XRD pattern in Fig. 3 and the TEM image in Fig. 4c show that anatase $\mathrm{TiO}_{2}$ nanocrystals with cube-like morphology were fabricated. Fig. 4d displays the corresponding HRTEM image of a single cube-like $\mathrm{TiO}_{2}$ nanoparticle. It shows a $d$-spacing of about $0.35 \mathrm{~nm}$, which is in good agreement with the (101) lattice plane of anatase $\mathrm{TiO}_{2}$, suggesting that the cube-like nanocrystals were well-crystallized. When a small amount of $\mathrm{NaOH}$ was added to the above reaction system, anatase $\mathrm{TiO}_{2}$ 

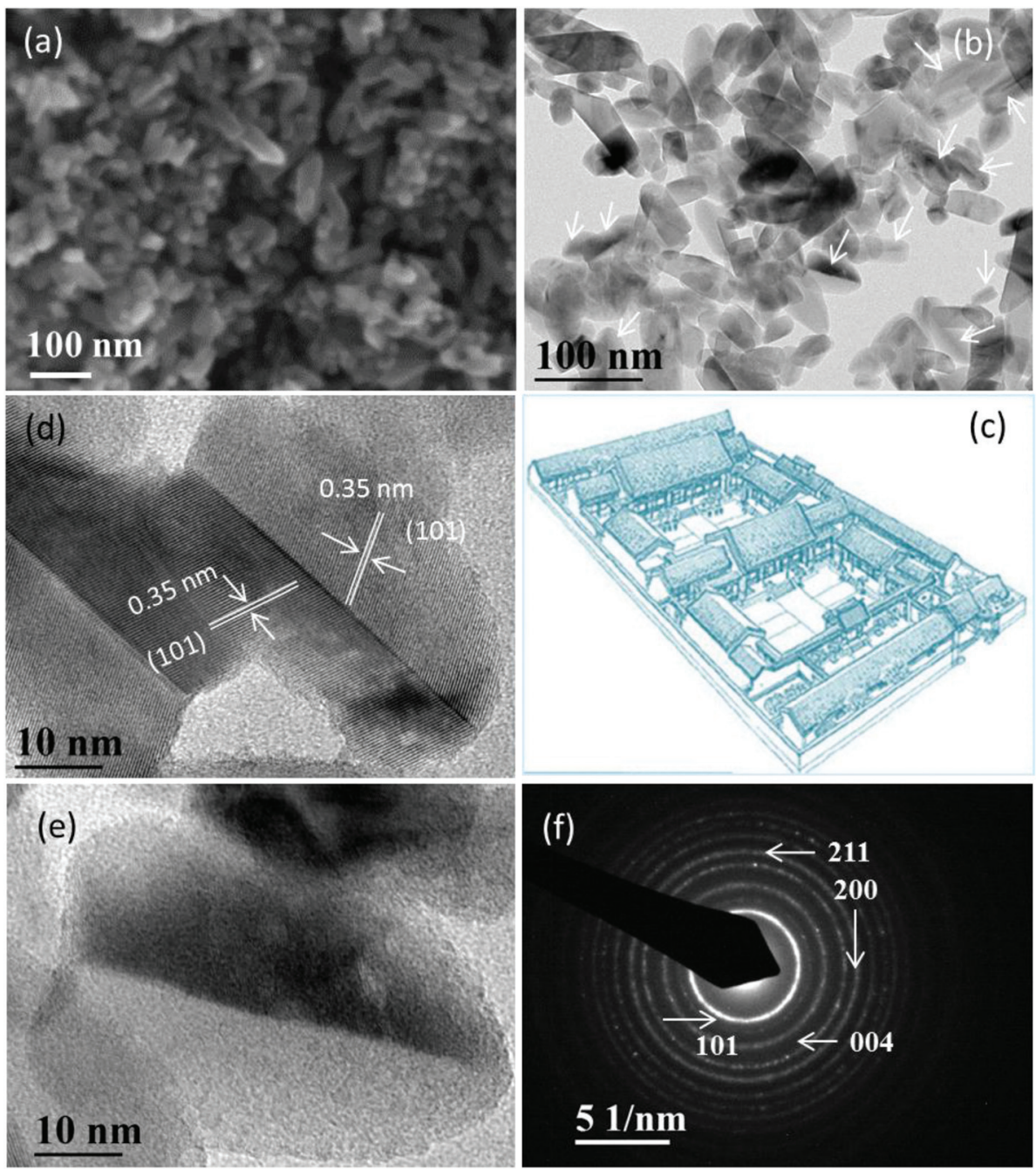

Fig. 2 (a) SEM, (b) TEM, and ( $d$ and e) HRTEM images, and (f) SAED pattern of the as-synthesized twinned $\mathrm{TiO}_{2}$ anatase nanocrystals. (c) Photograph of a Beijing traditional courtyard.

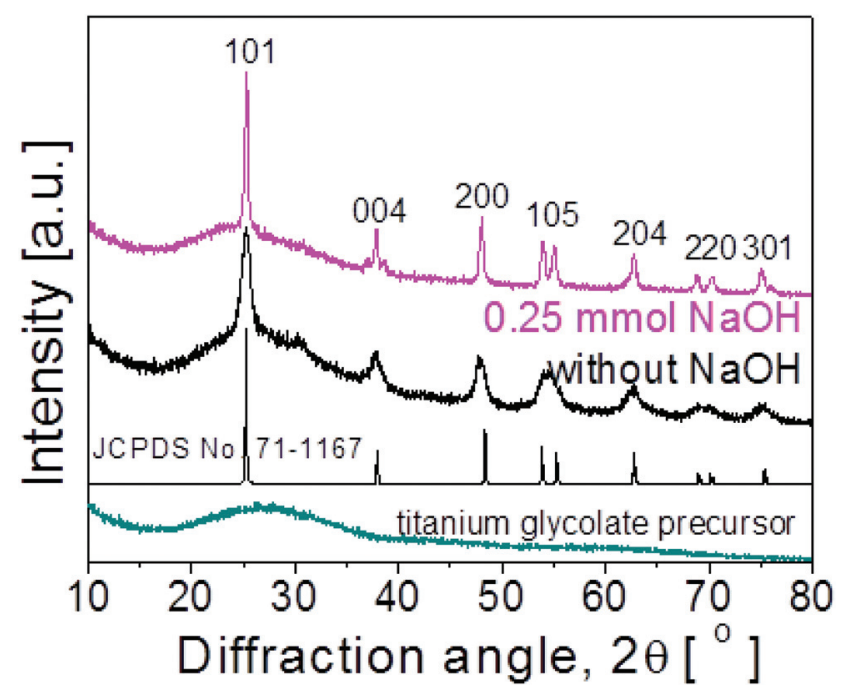

Fig. 3 XRD patterns of the titanium glycolate precursor and $\mathrm{TiO}_{2}$ products synthesized under different conditions. nanocrystals were still formed as shown in the TEM image in Fig. 4e. Interestingly, the HRTEM image in Fig. 4f indicates that the as-formed nanocrystals have a twinned structure like a fastigium. The above results reveal that the involvement of $\mathrm{NaOH}$ is the key parameter for the formation of the twinned $\mathrm{TiO}_{2}$ nanocrystals.

However, with an increase in the amount of $\mathrm{NaOH}$, the crystal phase and structure of the fabricated $\mathrm{TiO}_{2}$ nanocrystals changed greatly. As shown in Fig. 5, when the concentration of $\mathrm{NaOH}$ increased from 0.75 to $4 \mathrm{mmol}$ in the reaction system, $\mathrm{TiO}_{2}$ with a brookite phase was obtained, instead of anatase phase $\mathrm{TiO}_{2}$. As depicted in Fig. 6a-c, the SEM and TEM images show that rice-like brookite $\mathrm{TiO}_{2}$ nanoparticles were fabricated in the presence of $0.75 \mathrm{mmol} \mathrm{NaOH}$. Furthermore, in Fig. 6d-f, it was found that large amounts of particulates and fewer rice-like nanoparticles were obtained when $1 \mathrm{mmol} \mathrm{NaOH}$ was involved in the reaction system. When further increasing the concentration of $\mathrm{NaOH}$, the distribution of different-shaped brookite $\mathrm{TiO}_{2}$ nanoparticles 


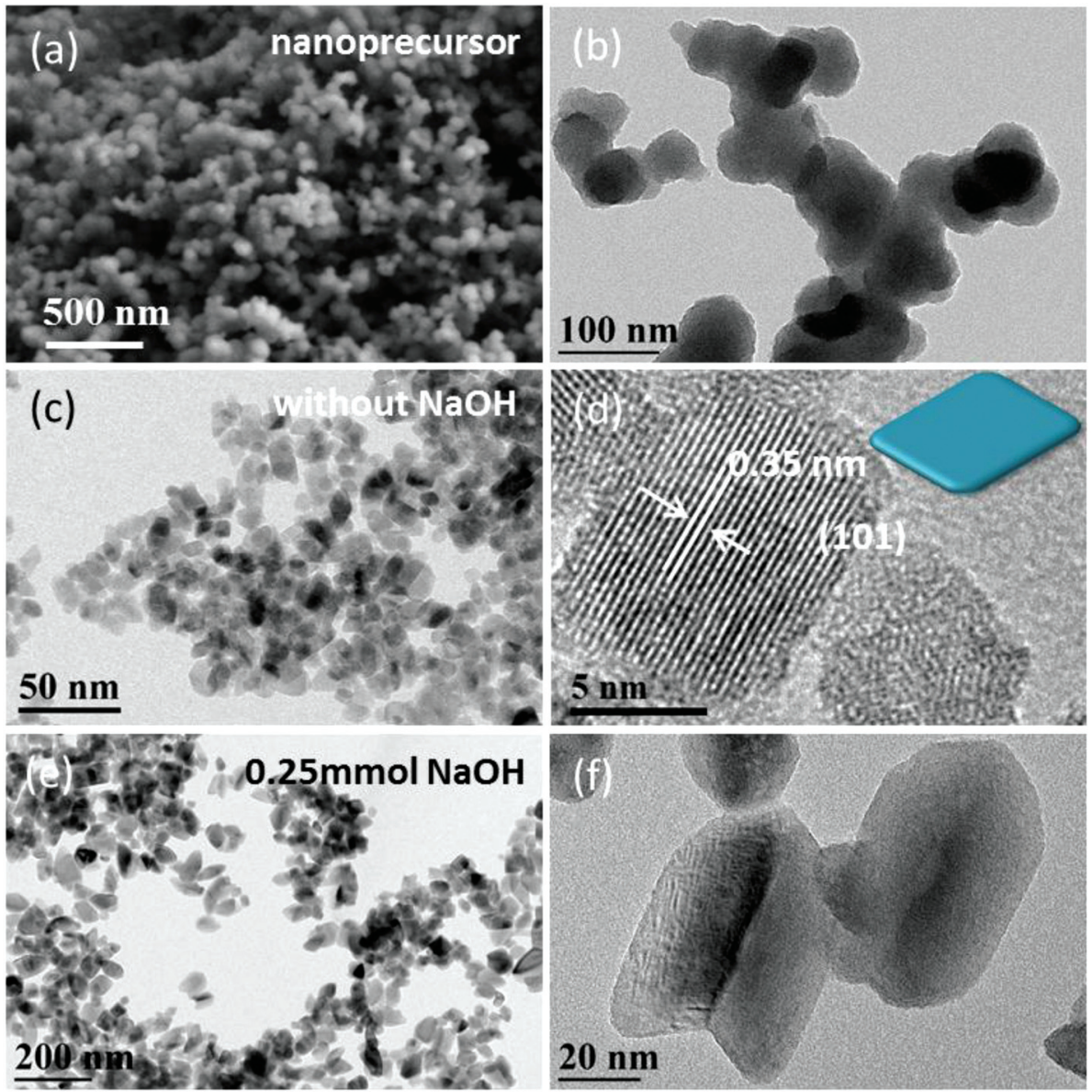

Fig. 4 (a and b) SEM and TEM images of the titanium glycolate precursor; (c and d) TEM images of the $\mathrm{TiO}_{2}$ products synthesized without $\mathrm{NaOH}_{\text {; }}$ (e and f) TEM images of the $\mathrm{TiO}_{2}$ products synthesized with $0.25 \mathrm{mmol} \mathrm{NaOH}$.

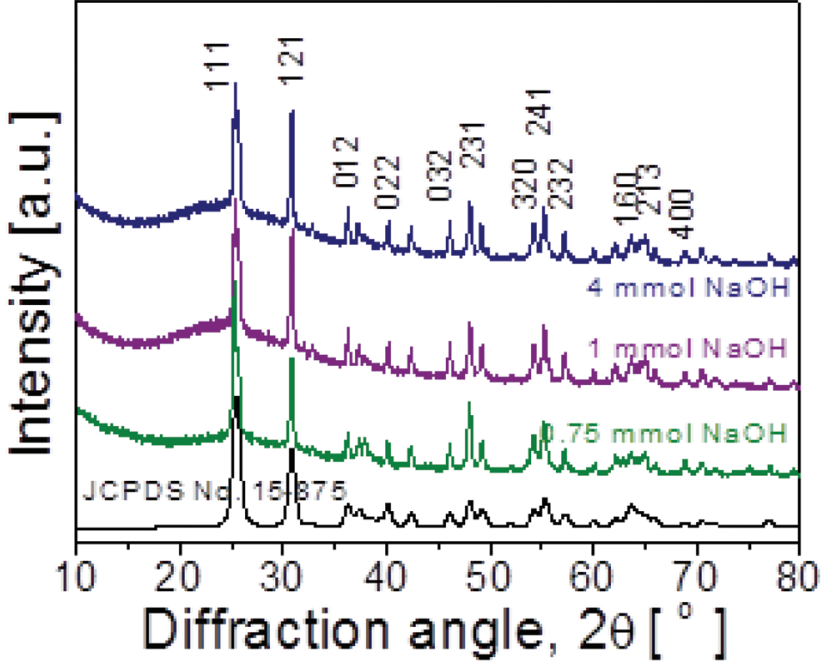

Fig. 5 XRD patterns of the $\mathrm{TiO}_{2}$ products synthesized with different concentrations of $\mathrm{NaOH}$.

changed. As displayed in Fig. $6 \mathrm{~g}-\mathrm{i}$, in the presence of $4 \mathrm{mmol}$ $\mathrm{NaOH}$, the final products mainly consisted of rice-like nanoparticles.
The above results further confirm that incorporating $\mathrm{NaOH}$ into the reaction system could achieve the tailoring of the crystal phase and morphology of the titanium oxide nanocrystals from the titanium glycolate precursor. Scheme 1 illustrates the formation of titanium oxide nanocrystals with different crystal phases and structures through the use of different amounts of $\mathrm{NaOH}$ in the reaction system. It is well-known that $\mathrm{TiO}_{2}$ has three main phases, anatase, brookite and rutile, but solution-phase synthesis strategies for $\mathrm{TiO}_{2}$ generally favour the formation of anatase structures. One of the main reasons for this is that the surface energy of anatase is lower than that of rutile and brookite. ${ }^{33,34}$ However, the nucleation and growth of different polymorphs of $\mathrm{TiO}_{2}$ is also determined by the involvement of the precursor, which depends on the reagents used in the reaction system. For example, Coronado et al. synthesized anatase nanoparticles using acetic acid from amorphous titania, while they obtained phase-pure rutile and brookite nanoparticles with hydrochloric acid at a different concentration. ${ }^{35}$ Zhao et al. also found that the initially formed precursor of $\left[\mathrm{Ti}(\mathrm{OH})_{4}\left(\mathrm{OH}_{2}\right)_{2}\right]$ from the starting material $\mathrm{TiOSO}_{4}$ in water could be easily transformed into the anatase phase, but the production of the brookite phase rather than other crystalline titania phases was favoured in the presence of highly con- 

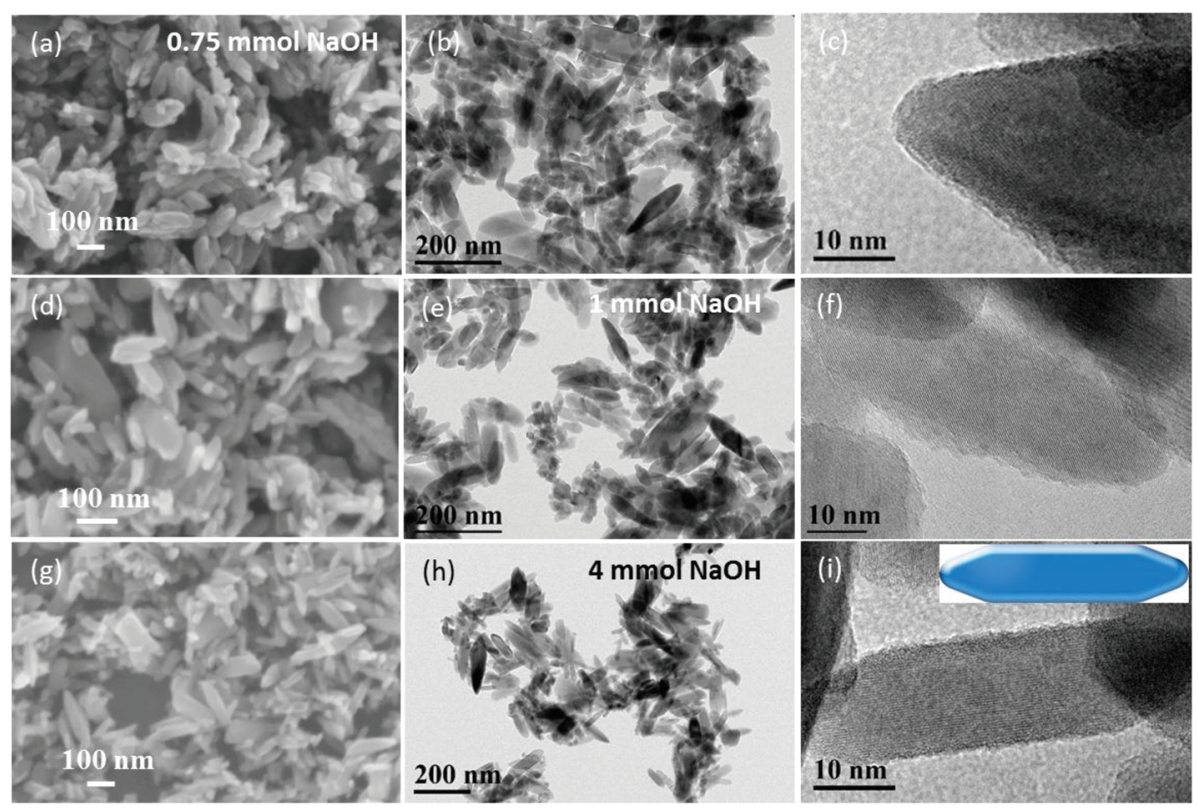

Fig. $6 \mathrm{SEM}$ and TEM images of the $\mathrm{TiO}_{2}$ products synthesized with the use of different amounts of $\mathrm{NaOH}$ : (a-c) $0.75 \mathrm{mmol}$, (d-f) $1 \mathrm{mmol}$, and ( $\left.\mathrm{g}-\mathrm{i}\right)$ $4 \mathrm{mmol}$.

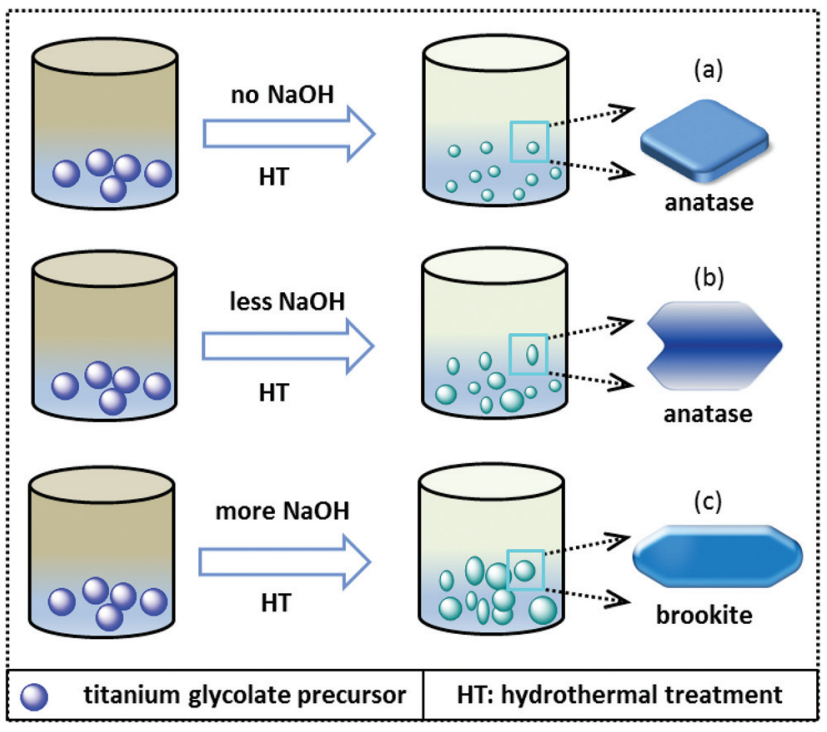

Scheme 1 Illustration of the phase and structure tailoring of titanium oxide nanocrystals in the presence of different concentrations of $\mathrm{NaOH}$.

centrated $\mathrm{OH}^{-} .{ }^{36}$ Based on the above previous reports, we proposed that the titanium glycolate precursor could initially steadily convert into the building unit monomers of $\mathrm{TiO}_{2}$ in the hydrothermal reaction system. Once the concentration of monomers reaches super-saturation, fast nucleation would occur, and a lot of crystal seeds would start to come out during the reaction period. However, the involvement of $\mathrm{OH}^{-}$could affect the kinetics and thermodynamics in the nucleation and growth of such crystal seeds, resulting in the control of the crystal phase and structure. As the results revealed, the tita- nium glycolate precursor hydrothermally treated with a slightly lower concentration of $\mathrm{OH}^{-}$species could result in the formation of twinned anatase nanocrystals. Meanwhile, with the incorporation of highly concentrated $\mathrm{OH}^{-}$into the present system, the precursor could be transformed into the brookite phase with a rice-like structure through a dissolution-recrystallization and subsequent crystal phase transformation process. Our understanding of the formation mechanism is limited and further study of the influence of additives on the structure and phase transformation of titanium oxides is still in progress.

Diffuse reflectance spectroscopy was used to characterize the optical absorption properties of the as-obtained $\mathrm{TiO}_{2}$ materials. To compare the optical and related photocatalytic properties, the samples prepared in the presence of $0,0.5$ and $4 \mathrm{mmol} \mathrm{NaOH}$, corresponding to anatase, twinned anatase, and brookite $\mathrm{TiO}_{2}$ nanocrystals, respectively, were investigated in the following experiments. As shown in Fig. 7a, the UV-Vis diffuse reflectance spectra of the as-synthesized $\mathrm{TiO}_{2}$ nanocrystals demonstrate that the products have different absorption edges in the UV-visible light region. Fig. 7b shows the plot of $(\alpha h \nu)^{1 / 2}$ versus photon energy $(h \nu)$ for the as-synthesized $\mathrm{TiO}_{2}$ nanocrystals, where $\alpha, \nu$, and $h$ are the absorption coefficient, the light frequency, and a constant, respectively. The band gap energy ( $E_{\mathrm{g}}$ value) of the anatase $\mathrm{TiO}_{2}$ nanocrystals estimated from the plot of $(\alpha h \nu)^{1 / 2}$ versus photon energy $(h \nu)$ was about $3.06 \mathrm{eV}$. However, the band gap energy of both the twinned anatase and brookite $\mathrm{TiO}_{2}$ nanocrystals is narrower than that of the anatase $\mathrm{TiO}_{2}$ nanocrystals (shown in Table 1), which confirms that the crystal phase and structure of $\mathrm{TiO}_{2}$ have a significant impact on the optical properties and offer a way of tuning the band gap. The valence band $\left(E_{\mathrm{VB}}\right)$ and conduction 



Fig. 7 (a) UV-vis diffuse reflectance spectra and (b) plots of $(\alpha h \nu)^{1 / 2}$ versus photon energy $(h \nu)$ of the as-synthesized $\mathrm{TiO}_{2}$ samples.

Table 1 Physicochemical properties, band gap, band edges, BET surface areas and photocatalytic $\mathrm{H}_{2}$ evolution capability of the as-synthesized $\mathrm{TiO}_{2}$ nanocrystals

\begin{tabular}{lrlllc}
\hline Sample & $\begin{array}{l}S_{\mathrm{BET}} \\
\left(\mathrm{m}^{2} \mathrm{~g}^{-1}\right)\end{array}$ & $\begin{array}{l}\text { Band } \\
\text { gap }(\mathrm{eV})\end{array}$ & $\begin{array}{l}E_{\mathrm{CB}} \\
(\mathrm{eV})\end{array}$ & $\begin{array}{l}E_{\mathrm{VB}} \\
(\mathrm{eV})\end{array}$ & $\begin{array}{l}\mathrm{H}_{2} \text { generation } \\
\left(\mu \mathrm{mol} \mathrm{g} \mathrm{g}^{-1}\right)\end{array}$ \\
\hline Anatase $\mathrm{TiO}_{2}$ & 141.19 & 3.06 & -0.22 & 2.84 & 104.54 \\
Twinned anatase $\mathrm{TiO}_{2}$ & 76.84 & 2.96 & -0.17 & 2.79 & 1272.66 \\
Brookite $\mathrm{TiO}_{2}$ & 54.98 & 2.87 & -0.13 & 2.74 & 182.76
\end{tabular}

band $\left(E_{\mathrm{CB}}\right)$ edge of the $\mathrm{TiO}_{2}$ nanocrystals at the point of zero charge can be calculated according to the empirical equation $E_{\mathrm{VB}}=X-E^{\mathrm{e}}+0.5 E_{\mathrm{g}}$, in which $X$ is the electronegativity of $\mathrm{TiO}_{2}$ $(5.81 \mathrm{eV}), E^{\mathrm{e}}$ is the energy of free electrons on the hydrogen scale (about $4.5 \mathrm{eV}$ ), $E_{\mathrm{g}}$ is the band gap energy of the semiconductor, and $E_{\mathrm{CB}}$ can be determined using $E_{\mathrm{CB}}=E_{\mathrm{VB}}-E_{\mathrm{g}}$. The $E_{\mathrm{VB}}$ and $E_{\mathrm{CB}}$ of the samples were calculated and are summarized in Table 1 . Typically, all three kinds of $\mathrm{TiO}_{2}$ nanocrystals have a suitable bandgap to harvest photons and a more negative bottom level of the conduction band than the redox potential of $\mathrm{H}^{+} / \mathrm{H}_{2}$, which is a thermodynamic requirement for hydrogen-evolution semiconductor photocatalysts. ${ }^{37}$ In other words, when incident light possessing energy greater than the band gap hits these $\mathrm{TiO}_{2}$ materials, the photo-generated electrons could reduce the protons or water molecules on the surface of $\mathrm{TiO}_{2}$ into molecular hydrogen.

Photocatalytic hydrogen evolution over the different $\mathrm{TiO}_{2}$ nanocrystals was evaluated using methanol solution (vol 20\%) as a sacrificial reagent under artificial sunlight irradiation. It was found that no $\mathrm{H}_{2}$ generation was measured without any photocatalyst or light irradiation. These results confirmed that achieving photocatalytic $\mathrm{H}_{2}$ production requires the use of a $\mathrm{TiO}_{2}$ photocatalyst as well as the involvement of light irradiation. Fig. 8a and b display the capability and corresponding evolution rates of photocatalytic $\mathrm{H}_{2}$ evolution using the different $\mathrm{TiO}_{2}$ photocatalysts. It was observed that the anatase $\mathrm{TiO}_{2}$ nanocrystals exhibited photocatalytic $\mathrm{H}_{2}$ performance with a hydrogen generation rate of $104.54 \mu \mathrm{mol} \mathrm{g}{ }^{-1} \mathrm{~h}^{-1}$, while the brookite $\mathrm{TiO}_{2}$ nanocrystal photocatalyst had a hydrogen generation rate of $182.76 \mu \mathrm{mol} \mathrm{g}{ }^{-1} \mathrm{~h}^{-1}$. However, when the twinned anatase $\mathrm{TiO}_{2}$ nanocrystals were used as the photocatalyst, they showed remarkably enhanced photocatalytic $\mathrm{H}_{2}$ generation capability with an evolution rate of 1272.66 $\mu \mathrm{mol} \mathrm{g}^{-1} \mathrm{~h}^{-1}$. The hydrogen evolution rate value of twinned anatase $\mathrm{TiO}_{2}\left(1272.66 \mu \mathrm{mol} \mathrm{g}{ }^{-1} \mathrm{~h}^{-1}\right)$ was significantly larger than that of commercial P25 $\left(3.64 \mu \mathrm{mol} \mathrm{g}{ }^{-1} \mathrm{~h}^{-1}\right){ }^{31}$ In addition, it exhibited higher efficiency for hydrogen generation compared to porous $\mathrm{TiO}_{2}$ hollow spheres $\left(21.2 \mu \mathrm{mol} \mathrm{g}{ }^{-1} \mathrm{~h}^{-1}\right),{ }^{38} 3 \mathrm{D}$ flowerlike $\mathrm{TiO}_{2}$ nanosheets $\left(1000 \mu \mathrm{mol} \mathrm{g}{ }^{-1} \mathrm{~h}^{-1}\right),{ }^{39}$ and $\mathrm{TiO}_{2}$ nanoparticles $\left(13.7 \mu \mathrm{mol} \mathrm{g}{ }^{-1} \mathrm{~h}^{-1}\right){ }^{40}$ In particular, as shown in Fig. $8 \mathrm{c}$ and $\mathrm{d}$, the hydrogen evolution rate of the twinned $\mathrm{TiO}_{2}$ nanocrystals was still maintained at about $500.74 \mu \mathrm{mol} \mathrm{g}{ }^{-1} \mathrm{~h}^{-1}$ after three cycles, which is higher than that of both the anatase and brookite $\mathrm{TiO}_{2}$ nanocrystals, indicating that the twinned $\mathrm{TiO}_{2}$ nanocrystals have good stability towards hydrogen evolution.

It has been reported that the BET surface area and charge transfer have an influence on the photocatalytic hydrogen evolution capability of semiconductors. ${ }^{41}$ Herein the impact of the surface areas of the three kinds of different $\mathrm{TiO}_{2}$ nanocrystals was first studied using nitrogen adsorption and desorption measurements. As shown in Fig. 9, the nitrogen adsorptiondesorption isotherms of the three different $\mathrm{TiO}_{2}$ nanocrystals exhibit type II adsorption-desorption isotherms in the range of 0.5-1.0 $P / P_{0}$, indicated that the samples have a porous structure, which may result from the aggregation of small nanoparticles. The Brunauer-Emmett-Teller (BET) specific surface areas of the $\mathrm{TiO}_{2}$ nanocrystals were calculated and are listed in Table 1. It was found that the BET surface area of the anatase $\mathrm{TiO}_{2}$ nanocrystals was larger than that of twinned anatase $\mathrm{TiO}_{2}$, which was slightly higher than that of the brookite nanoparticles. However, the twinned anatase $\mathrm{TiO}_{2}$ nanocrystals exhibited the highest photocatalytic hydrogen generation capability, even though they did not have the largest surface area among the three samples. These results indicate that the surface area is not the main parameter influencing the $\mathrm{H}_{2}$ production performance of the three $\mathrm{TiO}_{2}$ samples. 

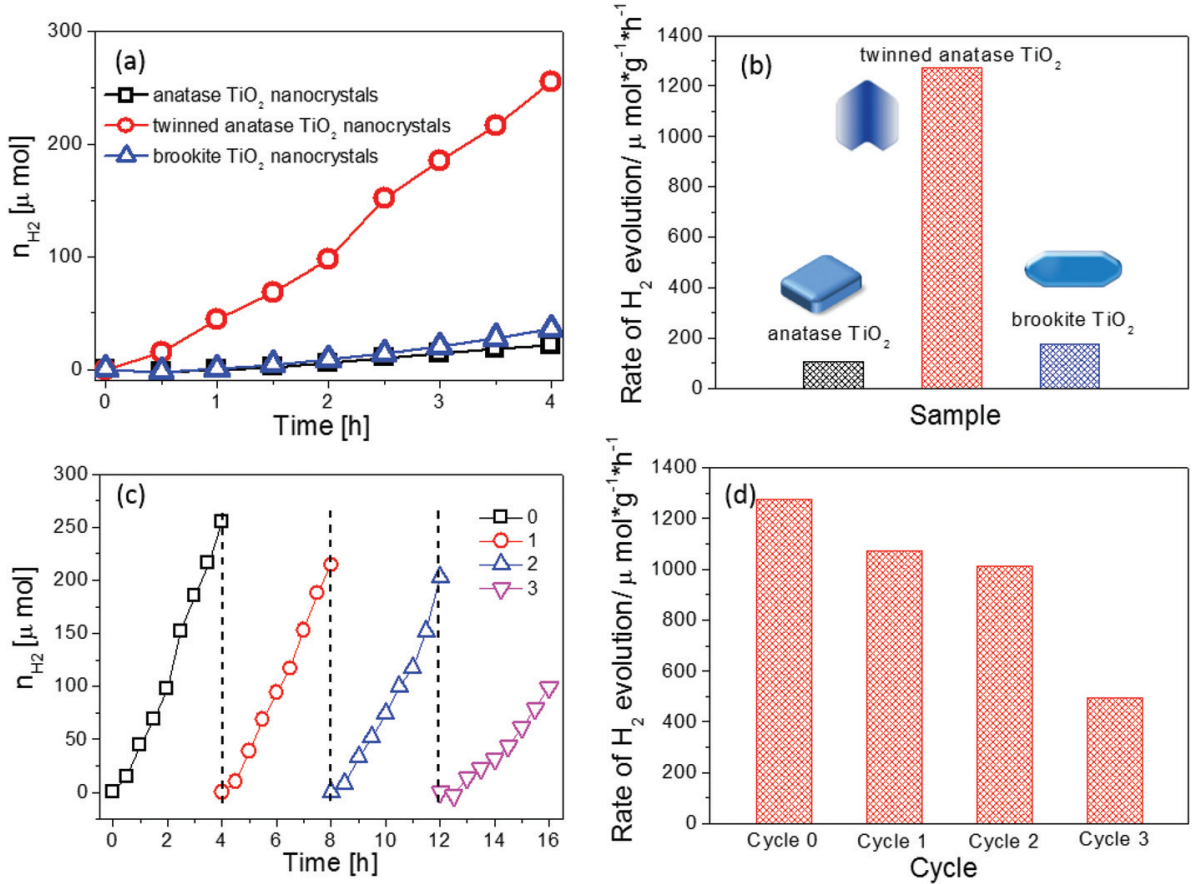

Fig. 8 (a) Photocatalytic hydrogen evolution performance and (b) evolution rate of the different $\mathrm{TiO}_{2}$ photocatalysts. (c) Recyclability of the hydrogen evolution behavior and (d) corresponding evolution rate over the twinned $\mathrm{TiO}_{2}$ nanocrystals.

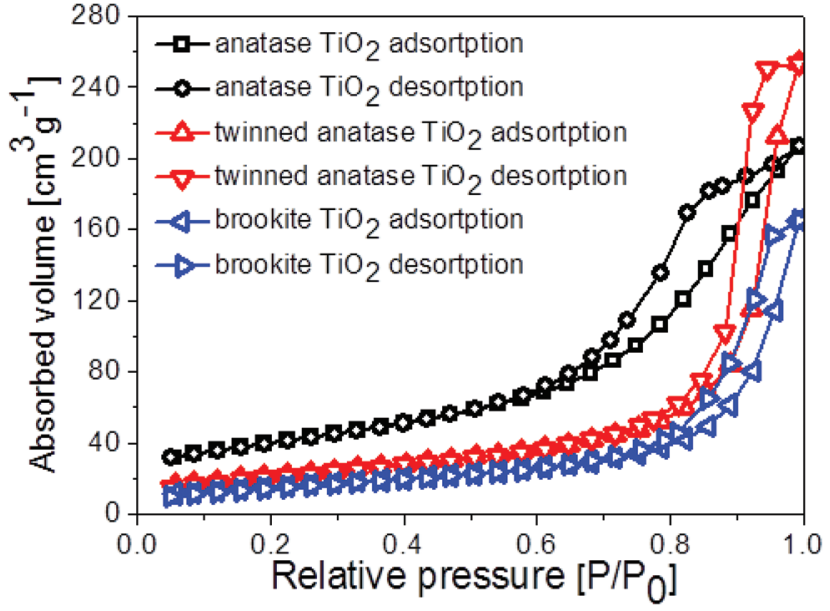

Fig. $9 \mathrm{~N}_{2}$ adsorption-desorption isotherms of the different $\mathrm{TiO}_{2}$ photocatalysts.

The photoluminescence spectrum (PL) could give useful information about the efficiency of electron-hole recombination and charge carrier trapping. Particularly, the recombination of photogenerated electrons and holes produced in a semiconductor could induce PL. Accordingly, a lower PL intensity of a semiconductor indicates faster separation and better transfer efficiency of photoinduced electron-hole pairs in the photocatalysis system, and therefore displays a higher photocatalytic capability. ${ }^{42-44}$ As can be seen in Fig. 10, the PL intensity of twinned anatase $\mathrm{TiO}_{2}$ was much lower than that of both

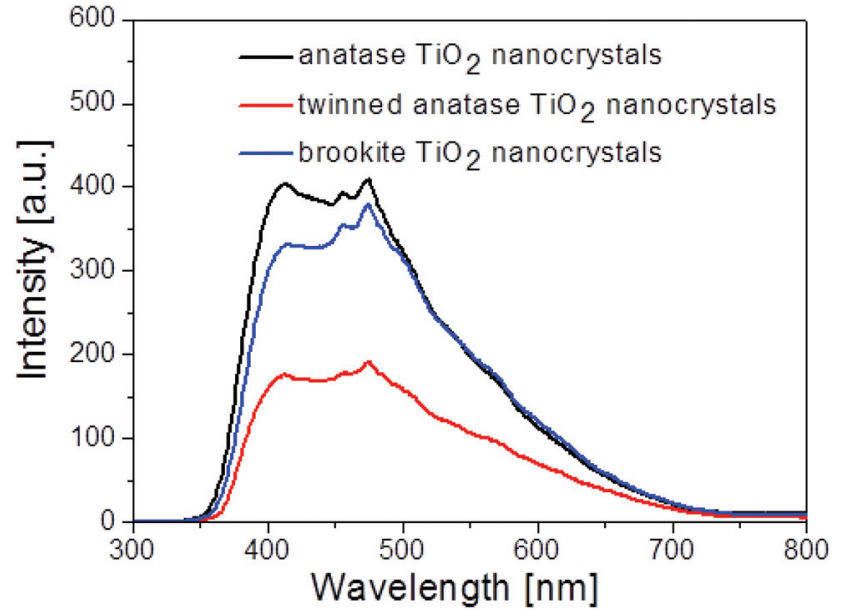

Fig. 10 Photoluminescence spectra of the different $\mathrm{TiO}_{2}$ photocatalysts.

anatase and brookite $\mathrm{TiO}_{2}$. This result suggested that the $\mathrm{TiO}_{2}$ nanocrystals with twinned structure could facilitate charge transfer so as to prohibit charge recombination in the $\mathrm{TiO}_{2}$ nanocrystals and finally result in a higher photocatalytic hydrogen evolution capability.

To better understand the behavior of photo-induced charge carriers in the three kinds of different $\mathrm{TiO}_{2}$ photocatalysts, additional electrochemical and photoelectrochemical experiments were also carried out. Fig. 11a shows the rapid and consistent photocurrent responses for each switch-on and -off 

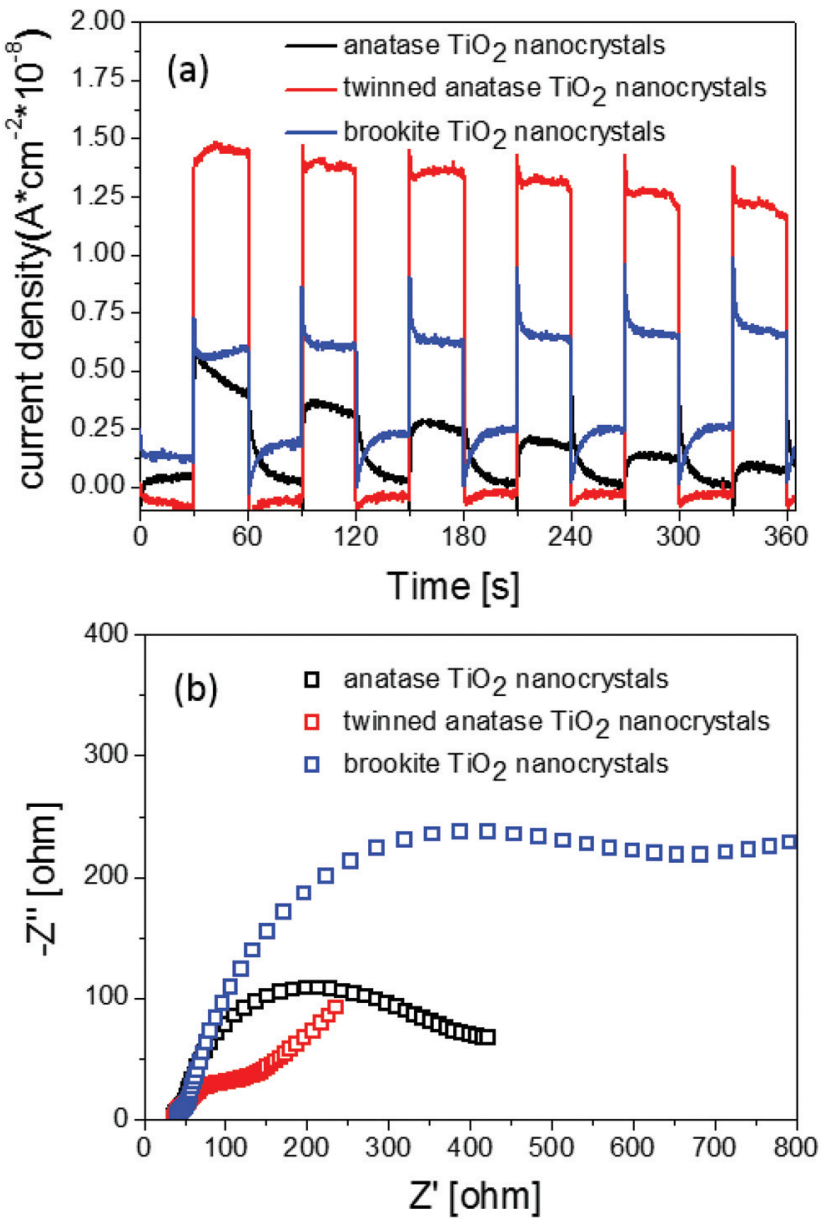

Fig. 11 (a) Electrochemical impedance spectra and (b) photocurrent responses of the different $\mathrm{TiO}_{2}$ samples.

event in multiple $30 \mathrm{~s}$ on-off cycles under simulated solar light irradiation. It is worth noting that the photocurrent density of the twinned anatase $\mathrm{TiO}_{2}$ electrode is much higher than that of both the anatase and brookite $\mathrm{TiO}_{2}$ nanocrystals. The promoted photocurrent response of the sample indicates higher efficiency and lower recombination rate of photogenerated electron-hole pairs in the twinned anatase $\mathrm{TiO}_{2}$ nanocrystals. $^{45,46}$ Fig. 11b shows the electrochemical impedance spectroscopy (EIS) Nyquist plots of the as-prepared three kinds of $\mathrm{TiO}_{2}$ photocatalysts. The arc radius on the EIS Nyquist plot of the twinned anatase $\mathrm{TiO}_{2}$ photocatalyst is smaller than that of the anatase and brookite $\mathrm{TiO}_{2}$ nanoparticles. As a matter of fact, in the EIS Nyquist plot, the smaller semicircle size indicates fast interfacial charge transfer in the semiconductor. ${ }^{47,48}$ The above result suggests that more effective interfacial charge transfer occurs on the twinned anatase $\mathrm{TiO}_{2}$ photocatalyst rather than anatase and brookite $\mathrm{TiO}_{2}$ under these conditions. Based on these results, it was concluded that the enhancement of the photocatalytic hydrogen evolution activity of the twinned anatase $\mathrm{TiO}_{2}$ nanocrystals was attributed to the faster separation of photogenerated carriers and lower recombination of photoinduced electron-hole pairs.

\section{Conclusions}

In summary, anatase $\mathrm{TiO}_{2}$ nanocrystals with a unique twinned nanostructure were successfully synthesized by a facile hydrothermal method from the hydrolysis of a titanium glycolate powder precursor. The composition and phase purity of the $\mathrm{TiO}_{2}$ products were characterized by XRD and Raman spectroscopy. The SEM, TEM, and HRTEM images showed that the involvement of $\mathrm{NaOH}$ was not only a key parameter for the formation of twinned anatase $\mathrm{TiO}_{2}$ nanocrystals, but could also be used to tailor the crystal phase of the as-synthesized $\mathrm{TiO}_{2}$ by changing its concentration. The photocatalysis activities of the as-prepared $\mathrm{TiO}_{2}$ products were evaluated by photocatalytic hydrogen generation under solar light irradiation. The excellent photocatalytic activity of twinned anatase $\mathrm{TiO}_{2}$ towards $\mathrm{H}_{2}$ production is ascribed to the efficient generation and separation of photoinduced electron-hole pairs. This novel approach using precursor nanoparticles offers a simple way to prepare $\mathrm{TiO}_{2}$ nanocrystals with unique twinned structures and excellent photocatalytic hydrogen production capability, as well as tailor the morphology and crystal phase, and is expected to provide a reference for fabricating other functional oxide nanocrystals with designed structures and promising applications.

\section{Acknowledgements}

This work was supported by the National Natural Science Foundation of China (21501137) and Department of Education of Hubei Province under the project of Science and Technology Innovation Team of Outstanding Young and Middle-aged Scientists (T201606). Dr Cheng would like to thank Mr Fan Tian (WIT) for his help with the BET surface area measurements. The authors are grateful for the assistance of Professor Rong Chen (WIT) with some of the measurements.

\section{References}

1 E. J. W. Crossland, N. Noel, V. Sivaram, T. Leijtens, J. A. Alexander-Webber and H. J. Snaith, Mesoporous $\mathrm{TiO}_{2}$ single crystals delivering enhanced mobility and optoelectronic device performance, Nature, 2013, 495(7440), 215-219.

2 S. Yang, B. X. Yang, L. Wu, Y. H. Li, P. Liu, H. Zhao, Y. Y. Yu, X. Q. Gong and H. G. Yang, Titania single crystals with a curved surface, Nat. Commun., 2014, 5, 5355.

3 H. G. Yang, C. H. Sun, S. Z. Qiao, J. Zou, G. Liu, S. C. Smith, H. M. Cheng and G. Q. Lu, Anatase $\mathrm{TiO}_{2}$ single crystals with a large percentage of reactive facets, Nature, 2008, 453(7195), 638-641.

4 Z. Sun, J. H. Kim, Y. Zhao, F. Bijarbooneh, V. Malgras, Y. Lee, Y.-M. Kang and S. X. Dou, Rational Design of 3D Dendritic $\mathrm{TiO}_{2}$ Nanostructures with Favorable Architectures, J. Am. Chem. Soc., 2011, 133(48), 19314-19317. 
5 H. Lin, L. Li, M. Zhao, X. Huang, X. Chen, G. Li and R. Yu, Synthesis of High-Quality Brookite $\mathrm{TiO}_{2}$ Single-Crystalline Nanosheets with Specific Facets Exposed: Tuning Catalysts from Inert to Highly Reactive, J. Am. Chem. Soc., 2012, 134(20), 8328-8331.

6 Y. Liu, A. Tang, Q. Zhang and Y. Yin, Seed-Mediated Growth of Anatase $\mathrm{TiO}_{2}$ Nanocrystals with Core-Antenna Structures for Enhanced Photocatalytic Activity, J. Am. Chem. Soc., 2015, 137(35), 11327-11339.

7 W. Zhou, W. Li, J.-Q. Wang, Y. Qu, Y. Yang, Y. Xie, K. Zhang, L. Wang, H. Fu and D. Zhao, Ordered Mesoporous Black $\mathrm{TiO}_{2}$ as Highly Efficient Hydrogen Evolution Photocatalyst, J. Am. Chem. Soc., 2014, 136(26), 9280-9283.

8 P. Zhou, H. Zhang, H. Ji, W. Ma, C. Chen and J. Zhao, Modulating the photocatalytic redox preferences between anatase $\mathrm{TiO}_{2}\{001\}$ and $\{101\}$ surfaces, Chem. Commun., 2017, 53(4), 787-790.

9 Y. Liu, K. Lan, S. Li, Y. Liu, B. Kong, G. Wang, P. Zhang, R. Wang, H. He, Y. Ling, A. M. Al-Enizi, A. A. Elzatahry, Y. Cao, G. Chen and D. Zhao, Constructing Three-Dimensional Mesoporous Bouquet-Posy-like $\mathrm{TiO}_{2}$ Superstructures with Radially Oriented Mesochannels and Single-Crystal Walls, J. Am. Chem. Soc., 2017, 139(1), 517-526.

10 C.-C. Wang and J. Y. Ying, Sol-Gel Synthesis and Hydrothermal Processing of Anatase and Rutile Titania Nanocrystals, Chem. Mater., 1999, 11(11), 3113-3120.

11 Y. Sang, B. Geng and J. Yang, Fabrication and growth mechanism of three-dimensional spherical $\mathrm{TiO}_{2}$ architectures consisting of $\mathrm{TiO}_{2}$ nanorods with $\{110\}$ exposed facets, Nanoscale, 2010, 2(10), 2109-2113.

12 K. Sabyrov, N. D. Burrows and R. L. Penn, Size-Dependent Anatase to Rutile Phase Transformation and Particle Growth, Chem. Mater., 2012, 25(8), 1408-1415.

13 H. Xu, S. Ouyang, P. Li, T. Kako and J. Ye, High-Active Anatase $\mathrm{TiO}_{2}$ Nanosheets Exposed with 95\% \{100\} Facets Toward Efficient $\mathrm{H}_{2}$ Evolution and $\mathrm{CO}_{2}$ Photoreduction, ACS Appl. Mater. Interfaces, 2013, 5(4), 1348-1354.

14 Y. Yu and D. Xu, Single-crystalline $\mathrm{TiO}_{2}$ nanorods: Highly active and easily recycled photocatalysts, Appl. Catal., B, 2007, 73(1-2), 166-171.

15 Y. Mao and S. S. Wong, Size- and Shape-Dependent Transformation of Nanosized Titanate into Analogous Anatase Titania Nanostructures, J. Am. Chem. Soc., 2006, 128(25), 8217-8226.

16 D. Wu, Z. Gao, F. Xu, J. Chang, S. Gao and K. Jiang, Anatase $\mathrm{TiO}_{2}$ nanocrystals enclosed by well-defined crystal facets and their application in dye-sensitized solar cell, CrystEngComm, 2013, 15(3), 516-523.

17 H. Zhu, X. Gao, Y. Lan, D. Song, Y. Xi and J. Zhao, Hydrogen Titanate Nanofibers Covered with Anatase Nanocrystals: A Delicate Structure Achieved by the Wet Chemistry Reaction of the Titanate Nanofibers, J. Am. Chem. Soc., 2004, 126(27), 8380-8381.

18 H. Y. Zhu, Y. Lan, X. P. Gao, S. P. Ringer, Z. F. Zheng, D. Y. Song and J. C. Zhao, Phase Transition between
Nanostructures of Titanate and Titanium Dioxides via Simple Wet-Chemical Reactions, J. Am. Chem. Soc., 2005, 127(18), 6730-6736.

19 P. Gao, D. Bao, Y. Wang, Y. Chen, L. Wang, S. Yang, G. Chen, G. Li, Y. Sun and W. Qin, Epitaxial Growth Route to Crystalline $\mathrm{TiO}_{2}$ Nanobelts with Optimizable Electrochemical Performance, ACS Appl. Mater. Interfaces, 2012, 5(2), 368-373.

20 H. Wang, H. Lin, Y. Long, B. Ni, T. He, S. Zhang, H. Zhu and $\mathrm{X}$. Wang, Titanocene dichloride $\left(\mathrm{Cp}_{2} \mathrm{TiCl}_{2}\right)$ as a precursor for template-free fabrication of hollow $\mathrm{TiO}_{2}$ nanostructures with enhanced photocatalytic hydrogen production, Nanoscale, 2017, 9(5), 2074-2081.

21 T. Ichijo, S. Sato and M. Fujita, Size-, Mass-, and DensityControlled Preparation of $\mathrm{TiO}_{2}$ Nanoparticles in a Spherical Coordination Template, J. Am. Chem. Soc., 2013, 135(18), 6786-6789.

22 J. Ye, W. Liu, J. Cai, S. Chen, X. Zhao, H. Zhou and L. Qi, Nanoporous Anatase $\mathrm{TiO}_{2}$ Mesocrystals: Additive-Free Synthesis, Remarkable Crystalline-Phase Stability, and Improved Lithium Insertion Behavior, J. Am. Chem. Soc., 2010, 133(4), 933-940.

23 X. Jiang, T. Herricks and Y. Xia, Monodispersed Spherical Colloids of Titania: Synthesis, Characterization, and Crystallization, Adv. Mater., 2003, 15(14), 1205-1209.

24 X. Jiang, Y. Wang, T. Herricks and Y. Xia, Ethylene glycolmediated synthesis of metal oxide nanowires, J. Mater. Chem., 2004, 14(4), 695-703.

25 L.-S. Zhong, J.-S. Hu, L.-J. Wan and W.-G. Song, Facile synthesis of nanoporous anatase spheres and their environmental applications, Chem. Commun., 2008, (10), 11841186.

26 G. Cheng, M. S. Akhtar, O. B. Yang and F. J. Stadler, Novel preparation of anatase $\mathrm{TiO}_{2}$ @reduced graphene oxide hybrids for high-performance dye-sensitized solar cells, ACS Appl. Mater. Interfaces, 2013, 5(14), 6635-6642.

27 G. Cheng and F. J. Stadler, Achieving phase transformation and structure control of crystalline anatase $\mathrm{TiO}_{2} @ \mathrm{C}$ hybrids from titanium glycolate precursor and glucose molecules, J. Colloid Interface Sci., 2015, 438, 169-178.

28 G. Cheng, F. Xu, J. Xiong, F. Tian, J. Ding, F. J. Stadler and R. Chen, Enhanced adsorption and photocatalysis capability of generally synthesized $\mathrm{TiO}_{2}$-carbon materials hybrids, Adv. Powder Technol., 2016, 27(5), 1949-1962.

29 G. Cheng, M. S. Akhtar, O. B. Yang and F. J. Stadler, Structure modification of anatase $\mathrm{TiO}_{2}$ nanomaterialsbased photoanodes for efficient dye-sensitized solar cells, Electrochim. Acta, 2013, 113, 527-535.

30 G. Cheng, F. Xu, J. Xiong, Y. Wei, F. J. Stadler and R. Chen, A novel protocol to design $\mathrm{TiO}_{2}-\mathrm{Fe}_{2} \mathrm{O}_{3}$ hybrids with effective charge separation efficiency for improved photocatalysis, Adv. Powder Technol., 2017, 28(2), 665-670.

31 Y. Wei, G. Cheng, J. Xiong, F. Xu and R. Chen, Positive Ni $\left(\mathrm{HCO}_{3}\right)_{2}$ as a novel cocatalyst for boosting photocatalytic hydrogen evolution capability of mesoporous $\mathrm{TiO}_{2}$ nanocrystals, ACS Sustainable Chem. Eng., 2017, 5, 5027-5038. 
32 N. Roy, Y. Sohn and D. Pradhan, Synergy of Low-Energy $\{101\}$ and High-Energy $\{001\} \quad \mathrm{TiO}_{2}$ Crystal Facets for Enhanced Photocatalysis, ACS Nano, 2013, 7(3), 25322540.

33 T. A. Kandiel, A. Feldhoff, L. Robben, R. Dillert and D. W. Bahnemann, Tailored Titanium Dioxide Nanomaterials: Anatase Nanoparticles and Brookite Nanorods as Highly Active Photocatalysts, Chem. Mater., 2010, 22(6), 20502060.

34 M. Cargnello, T. R. Gordon and C. B. Murray, SolutionPhase Synthesis of Titanium Dioxide Nanoparticles and Nanocrystals, Chem. Rev., 2014, 114(19), 9319-9345.

35 D. Reyes-Coronado, G. Rodríguez-Gattorno, M. E. EspinosaPesqueira, C. Cab, R. D. Coss and G. Oskam, Phase-pure $\mathrm{TiO}_{2}$ nanoparticles: anatase, brookite and rutile, Nanotechnology, 2008, 19(14), 145605.

36 M. Zhao, L. Li, H. Lin, L. Yang and G. Li, A facile strategy to fabricate large-scale uniform brookite $\mathrm{TiO}_{2}$ nanospindles with high thermal stability and superior electrical properties, Chem. Commun., 2013, 49(63), 7046-7048.

37 Y. Xu, M. Kraft and R. Xu, Metal-free carbonaceous electrocatalysts and photocatalysts for water splitting, Chem. Soc. Rev., 2016, 45(11), 3039-3052.

38 L. Li, S. Bai, W. Yin, S. Li, Y. Zhang and Z. Li, A novel etching and reconstruction route to ultrathin porous $\mathrm{TiO}_{2}$ hollow spheres for enhanced photocatalytic hydrogen evolution, Int. J. Hydrogen Energy, 2016, 41(3), 16271634.

39 J. Jitputti, T. Rattanavoravipa, S. Chuangchote, S. Pavasupree, Y. Suzuki and S. Yoshikawa, Low temperature hydrothermal synthesis of monodispersed flowerlike titanate nanosheets, Catal. Commun., 2009, 10(4), 378-382.
$40 \mathrm{~J}$. Yu, Y. Hai and B. Cheng, Enhanced Photocatalytic $\mathrm{H}_{2}$-Production Activity of $\mathrm{TiO}_{2}$ by $\mathrm{Ni}(\mathrm{OH})_{2}$ Cluster Modification, J. Phys. Chem. C, 2011, 115(11), 4953-4958.

$41 \mathrm{X}$. Zou and Y. Zhang, Noble metal-free hydrogen evolution catalysts for water splitting, Chem. Soc. Rev., 2015, 44(15), 5148-5180.

42 Q. Huang, S. Tian, D. Zeng, X. Wang, W. Song, Y. Li, W. Xiao and C. Xie, Enhanced Photocatalytic Activity of Chemically Bonded $\mathrm{TiO}_{2} /$ Graphene Composites Based on the Effective Interfacial Charge Transfer through the C-Ti Bond, ACS Catal., 2013, 3(7), 1477-1485.

43 P. Zhang, T. Wang, X. Chang and J. Gong, Effective Charge Carrier Utilization in Photocatalytic Conversions, Acc. Chem. Res., 2016, 49(5), 911-921.

44 A. Tanaka, K. Teramura, S. Hosokawa, H. Kominami and T. Tanaka, Visible light-induced water splitting in an aqueous suspension of a plasmonic $\mathrm{Au} / \mathrm{TiO}_{2}$ photocatalyst with metal co-catalysts, Chem. Sci., 2017, 8(4), 25742580.

45 J. Low, J. Yu, M. Jaroniec, S. Wageh and A. A. Al-Ghamdi, Heterojunction Photocatalysts, Adv. Mater., 2017, 29(20), 1601694.

46 K. Li, B. Peng and T. Peng, Recent Advances in Heterogeneous Photocatalytic $\mathrm{CO}_{2}$ Conversion to Solar Fuels, ACS Catal., 2016, 6(11), 7485-7527.

47 A. Migani and L. Blancafort, Excitonic Interfacial ProtonCoupled Electron Transfer Mechanism in the Photocatalytic Oxidation of Methanol to Formaldehyde on $\mathrm{TiO}_{2}(110)$, J. Am. Chem. Soc., 2016, 138(49), 16165-16173.

48 M. Nolan, A. Iwaszuk, A. K. Lucid, J. J. Carey and M. Fronzi, Design of Novel Visible Light Active Photocatalyst Materials: Surface Modified $\mathrm{TiO}_{2}$, Adv. Mater., 2016, 28(27), 5425-5446. 